\title{
A multi-scale study of the relationships between habitat use and the distribution and abundance patterns of three coral reef angelfishes (Pomacanthidae)
}

\author{
Janelle V. Eagle*, Geoffrey P. Jones, Mark I. McCormick \\ Department of Marine Biology, James Cook University, Townsville, Queensland 4811 Australia
}

\begin{abstract}
The degree to which species partition resources often depends on the spatial scale of the study. To investigate this, we examined the distribution and abundance patterns of 3 relatively rare pygmy angelfishes (family Pomacanthidae: Centropyge) among reef locations, depths and microhabitats at Lizard Island on the Great Barrier Reef. A strong association among species and between species and their habitat was found at some scales, but not others. On a broad scale, the abundances of the 3 species were highest at the same 4 sites (kilometres apart). These sites were all located at headlands, suggesting that the patterns of abundance may be in response to the topographic features of the island at this scale. Differences among species occurred at intermediate scales (10s to 100s of metres), where species were associated with different depth zones or reef locations. Centropyge vroliki occurred shallower than C. bicolor, while the depth distribution of C. bispinosa overlapped with both of these species. Laterally along the fringing reef, $C$. vroliki were more abundant in areas where both $C$. bicolor and $C$. bispinosa were also abundant, but these 2 latter species were not correlated with each other. The proportions of substratum types present in home patches differed among species, to some extent reflecting the benthic composition of the reef area where each occurred. However on a fine scale (metres), all 3 species appeared to use the same substratum type, which consisted of dead branching coral covered in algae, and occasionally formed multi-species groups. Species abundances were not correlated with this commonly used microhabitat, but rather the availability of the substrata characterizing the reef areas in which they were most abundant. Here, although Centropyge species use the same type of microhabitat, they may be an example of species that partition space on the basis of non-preferred resources. For example, all 3 species used home patches containing high proportions of overgrown corals; however where this habitat was not available, $C$. bicolor used sand and rubble habitat at the reef base, while $C$. vroliki used coral habitat on the reef crest. Most importantly, this study emphasizes that a multi-scale approach is necessary to determine appropriate scales for examining species associations and resource partitioning in reef fishes.
\end{abstract}

KEY WORDS: Centropyge $\cdot$ Pomacanthidae $\cdot$ Great Barrier Reef $\cdot$ Habitat use $\cdot$ Distribution patterns Multi-scale analysis $\cdot$ Spatial scale $\cdot$ Species associations

\section{INTRODUCTION}

The importance of resource partitioning to the coexistence of ecologically similar coral reef fish species

*E-mail: janelle.eagle@jcu.edu.au and its relationship to the high diversity that characterizes these assemblages have been the subject of much debate. Early studies on reef fish communities not only found them to be highly speciose assemblages, but also to be relatively generalised in terms of both diet and space requirements (Roughgarden 1974, Sale 
$1975,1977,1978)$. This appeared to conflict with competition theory, which argued that coexistence in diverse assemblages results from the partitioning of resources among species (Pianka 1966, MacArthur 1969, Colwell 1973). Early attempts to demonstrate that competition plays a role in habitat partitioning on coral reefs repeatedly failed (Doherty 1983, Roberts 1987, Jones 1988). As an alternative, it has been argued that diversity may be related to the variability in the supply of pelagic larvae and juvenile recruitment, at levels below which space would become saturated (Talbot et al. 1978, Doherty 1983, Victor 1983, Sale et al. 1984, Doherty \& Williams 1988). This variability may act to reduce the capacity for a competitively dominant species to eliminate an inferior competitor.

Since the pioneering work on reef fishes, numerous studies have documented distinct patterns of food and habitat utilisation among similar species. Examples can be found in a range of coral reef fish families including surgeonfishes (Robertson 1980, Waldner \& Robertson \& Gaines 1986, Robertson \& Lassig 1980), blennies (Clarke 1994), groupers (Shpigel \& Fishelson 1989), sandperch (Sano 1990), damselfishes (Ormond et al. 1996), butterflyfishes (Pitts 1991, McAfee \& Morgan 1996) and gobies (Munday et al. 1997). In addition, there is increasing evidence that inter-specific competitive interactions play a role in maintaining speciesspecific patterns in habitat use (Robertson 1984, 1996, Ebersole 1985, Robertson \& Gaines 1986, Clarke 1989).

There are a number of reasons why some studies emphasize ecological similarities among species, while others highlight their differences. Coral reef fishes are found in an environment which is structurally complex on a hierarchy of spatial scales (Sale 1991, 1998) and reef fish appear to respond to the environment at all spatial scales that have been examined (Williams 1991). For example, the species composition of fish assemblages have been found to vary across continental shelves (Williams 1991), along gradients of wave exposure (Talbot 1965, Williams 1982, Victor 1986), and depth (Waldner \& Robertson 1980, Eckert 1985, Fowler 1990, McCormick 1994, Green 1996), and among microhabitats (Itzkowitz 1977, Jones 1988, Jennings et al. 1996, Ormond et al. 1996). However, not all species respond to all gradients in habitat structure, and species may partition resources at some scales and not others. Consequently, multi-scale approaches should be used to identify appropriate scales to measure ecological similarity and differences among species.

Different levels of resource partitioning may be characteristic of different taxa. Ecological theories regarding processes which contribute to high diversity in coral reef fish assemblages have been constructed pri- marily on the results of studies on relatively common and speciose taxa, such as damselfish (Doherty 1983, Sale et al. 1984). However, coral reefs contain a large number of species that are locally rare even though the dispersive larval stage ensures relatively wide geographic distributions (Jones \& Kaly 1995). Patterns of resource partitioning in common taxa may not be representative of their rarer counterparts. If rarity results from low availability of preferred resources, then competition for these resources may be more intense among closely related rare species compared with more common ones. Alternatively, if rarity is due to inherent life history characteristics such as low reproductive output, recruitment rates, or mortality rates, then shared resources may be in abundant supply, and thus resource use among rare species may overlap to a greater degree than expected. An examination of patterns of resource use by rare species and their subsequent effects on distribution and abundance may give some indication of whether coexistence in rare species is maintained through resource partitioning. In addition, investigations of rare species may provide further clues as to the causes of diversity in reef fish assemblages as a whole.

Pygmy angelfishes (genus Centropyge) are a group of relatively rare but conspicuous reef fishes, with several congeners occurring on almost all tropical coral reefs. These characteristics make the pygmy angelfishes an ideal genus to compare resource utilization traits and determine how they may affect patterns of distribution. Pygmy angelfishes are known to be highly site-attached with the females holding foraging territories, while the males defend females from other males throughout the year (Lobel 1978, Moyer \& Nakazono 1978, Bauer \& Bauer 1981, Moyer et al. 1983, Aldenhoven 1984, Sakai \& Kohda 1997). Although some information has been published on the habitat requirements of particular Centropyge species (Moyer \& Nakazono 1978, Moyer et al. 1983, Aldenhoven 1984, Sakai \& Kohda 1997), there are no quantitative studies to date that compare habitat use among more than 1 species of Centropyge.

This study investigated the distribution and abundance patterns of 3 pygmy angelfishes, Centropyge bicolor, C. vroliki and C. bispinosa, at multiple spatial scales. The aim was to determine appropriate scales for examining ecological partitioning among these species. The spatial scales examined were (1) a large spatial scale $(\geq 1000 \mathrm{~m}$ ) encompassing an exposure gradient, (2) a medium spatial scale (10 to $100 \mathrm{~m})$ along a depth gradient, and (3) fine-scale (1 to $10 \mathrm{~m}$ ) patterns of dispersion within habitats. The first 2 scales relate to environmental gradients which reef fish are known to respond to, while the smallest scale relates to the extent of movement of Centropyge individuals based 
on the behavioural observations of a previous study (Aldenhoven 1986). Using this sampling hierarchy, we were able to identify scales at which habitat resources appear to influence patterns of angelfish abundance and distribution.

\section{METHODS}

Study location and species. This study was carried out at Lizard Island, a continental island located approximately $35 \mathrm{~km}$ off the coast of Australia in the northern sector of the Great Barrier Reef $\left(14^{\circ} 40^{\prime} \mathrm{S}\right.$, $\left.145^{\circ} 28^{\prime} \mathrm{E}\right)$. The fringing reefs surrounding the island were divided into 3 sites according to their exposure to the prevailing southeasterly trade winds (Fig. 1a): sheltered (S), moderately exposed or oblique to the prevailing wind (M) and directly exposed (D) (Choat \& Bellwood 1985). At Lizard Island, pygmy angelfishes (genus Centropyge) are rare in terms of local abundance (sensu Gaston 1994) comprising less than half a percent of the demersal reef fish community (Syms \& Jones unpubl.). They are, however, easily identifiable by their small size and distinct colour patterns. Three species, C. bicolor, C. vroliki and C. bispinosa, were found in the sites surveyed for this study.

Sampling design. A total of 9 sites, 3 within each of the 3 exposures at Lizard Island (i.e. S1-S3, M1-M3 and D1-D3) were censused visually for Centropyge. Four replicate $100 \times 10 \mathrm{~m}$ transects were conducted at each of the 9 sites surveyed, except for one site (D3), where only 3 transects were censused due to adverse weather conditions. For each transect, a $100 \mathrm{~m}$ long tape was placed approximately $3 \mathrm{~m}$ below and parallel to the reef crest, and pygmy angelfish occurring within $5 \mathrm{~m}$ either side of the tape were counted (Fig. 1b). Such a large sampling unit was required due to the rarity of Centropyge species. Along each transect, the depth of each Centropyge was recorded, and their locations within the transect were mapped to provide comparative information on the degree of dispersion for each species. Data from 2 additional sites, 1 sheltered (Mermaid Cove) and 1 exposed (Bird Islet), were included in the analysis of the smaller scale distribution patterns.

The availability of microhabitats at 7 of the 9 sites used in the fish censuses were quantified by sampling in 3 reef zones: crest, slope and base. Two sites (D2 and D3) were excluded from the data collections due to adverse weather conditions. The same sampling design was used to survey the available habitat as was used for the visual censuses. Four transects $100 \mathrm{~m}$ long were carried out at each site, and within these transects the habitat was surveyed separately for each of 3 reef zones, the crest, slope and base (Fig. 1b). Ten ran-

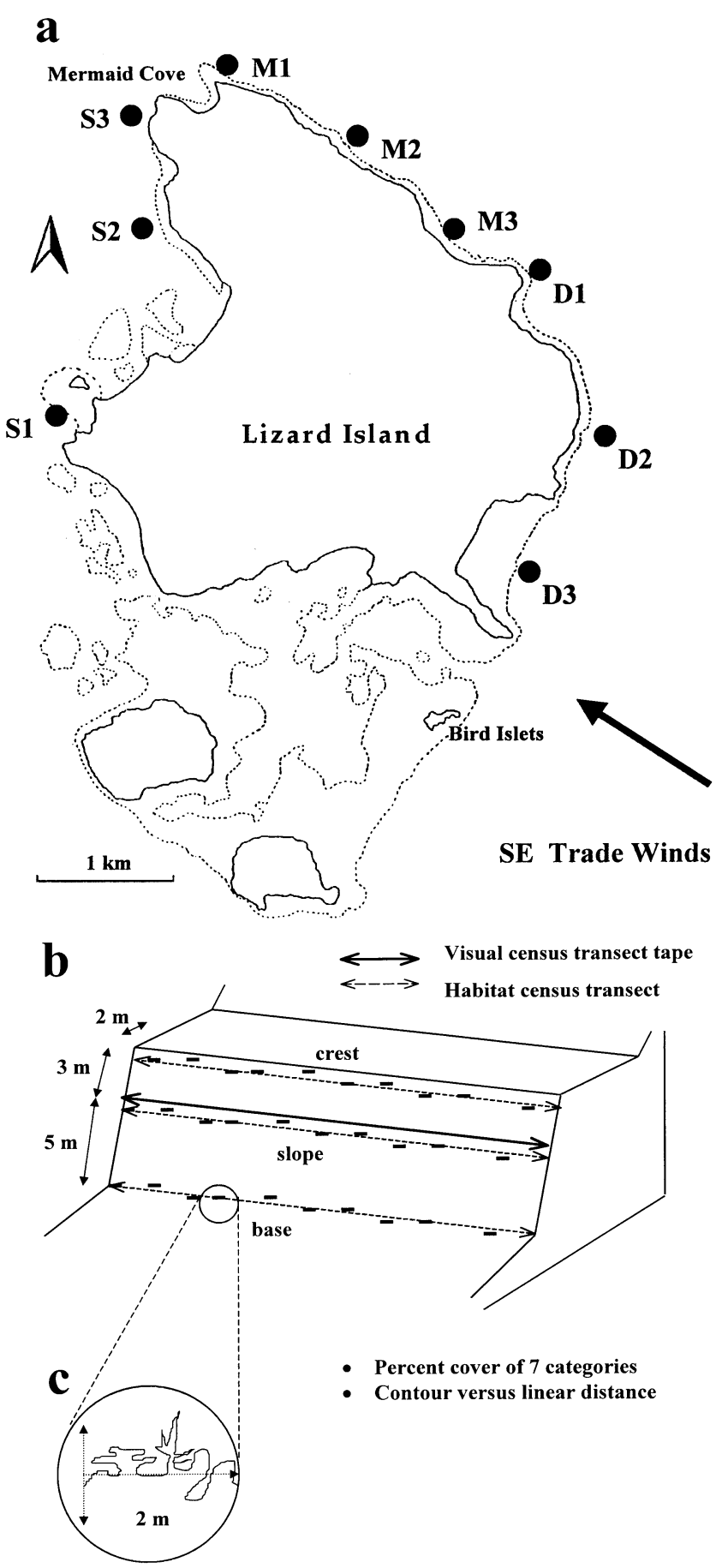

Fig. 1. (a) Map of Lizard Island $\left(14^{\circ} 40^{\prime} \mathrm{S}, 145^{\circ} 28^{\prime} \mathrm{E}\right)$, showing the main sites used in this study and the direction of the prevailing wind. Codes refer to the relative degree of exposure: $\mathrm{S}=$ sheltered, $\mathrm{M}=$ moderately exposed, $\mathrm{D}=$ directly exposed. (b) Overlay of fish census and habitat availability transects. Within each 'fish' transect, 3 'habitat' transects were laid out along the reef crest, slope and base, in which 10 discrete $2 \mathrm{~m}$ sections were surveyed. (c) Data recorded for each $2 \mathrm{~m}$ section of habitat surveyed included the topographical complexity (contour vs linear distance) and percentage cover of 7 substratum categories (see Table 1) 
domly selected $2 \mathrm{~m}$ sections were surveyed along each of these zones. For each $2 \mathrm{~m}$ section, the topographic complexity (ratio of contoured length to $2 \mathrm{~m}$ ) was measured and the intercept lengths of 7 substratum categories (Table 1) along the $2 \mathrm{~m}$ section were quantified to estimate percentage composition (Fig. 1c).

To determine the characteristics of the reef substrata used by each of the 3 species of Centropyge, $2 \mathrm{~m}$ line transects laid parallel to the reef crest were surveyed over the home patches of 45 groups of Centropyge vroliki, 43 of C. bicolor and 22 of C. bispinosa. The home patch was defined as the area of reef into which members of a particular social group would retreat most often when disturbed, and around which most of their foraging was based. Home patches were usually based around an outcrop of rock or coral and contained portions of territories of individual fish. In addition, 13 home patches were surveyed which were occupied by 2 or more species of Centropyge.

Analysis of distribution and abundance. Total abundance estimates of the 3 species of Centropyge were compared among exposures and sites (nested in exposures) using MANOVA followed by a non-metric multidimensional scaling (MDS). To examine the relative abundances of each species of Centropyge among sites, an MDS was carried out using a Quantitative Symmetric Kulezynski (QSK) matrix to preserve the rank order of dissimilarities. A complete linkage cluster analysis using Ward's method on the dissimilarities from the matrix was used to group sites according to their similarity in relative abundance of the 3 species, and this was superimposed on the first 2 dimension axes.

Pairwise Pearson's correlations were used to test for associations between species of Centropyge at the transect level. Data were $\log _{10}(x+1)$ transformed to reduce the variation resulting from low numbers. To assess patterns in inter-specific associations at an even smaller spatial scale (within $10 \times 10 \mathrm{~m}$ sections of reef), the presence of each species relative to the presence of the others were compared using chi-square test of independence with an adjusted alpha value (Bonferroni method) for multiple comparisons. At this fine scale, the presence and absence of each species were compared rather than absolute numbers to overcome the bias of different group sizes among the species. Distributions which were found not to be independent were tested for the nature of their association (positive or negative) using the phi coefficient of association (Sokal $\&$ Rohlf 1995). These data were obtained from the mapped distributions of fish within each transect using the co-ordinates recorded during visual censuses.

To compare the relative depth distributions among the 3 species of Centropyge, the depths recorded for each individual were standardised to mean low water tide. The depth frequency distributions across all sites were then compared among species using Kolmogorov-Smirnov tests with an adjusted alpha value (Bonferroni method) for multiple comparisons (Sokal \& Rohlf 1995).

Analysis of habitat use. Similarities in the habitat occurring in home patches among Centropyge species were examined by comparing the relative proportion of substratum categories, and the variability in the micro-topographic reef profiles. Out of the 13 shared patches censused, 6 were occupied by groups of both Centropyge bicolor and C. vroliki, 3 by all 3 species, and 2 each by $C$. bispinosa with $C$. bicolor, and $C$. bispinosa with $C$. vroliki. To determine whether the 3 species differed significantly in their habitat use, data were analysed using a 1-way MANOVA. Pillais Trace statistic was used to determine significance. A canonical discriminant analysis (CDA) was used to display similarities in habitat use by plotting each of the 3 species in a 2-dimensional space. Confidence ellipses $(95 \%)$ were calculated for all the group mean centroids using the formula:

$$
95 \% \mathrm{CL}=\sqrt{ }\left(\chi_{2}^{2}, 0.05 / n\right)
$$

where $n=$ the number of replicates (Seber 1984).

Table 1. Seven broad substratum categories used to define reef microhabitat

\begin{tabular}{|c|c|}
\hline Algae & $\begin{array}{l}\text { 1. Algae (flat): Non-complex reef substrata (e.g. massive corals, reef base) overgrown with epilithic } \\
\text { algae or macroalgae } \\
\text { 2. Algae (compl): Complex reef substrata (e.g. branching corals) overgrown with epilithic algae or } \\
\text { macroalgae }\end{array}$ \\
\hline Sand \& rubble & 3. Calcareous or silicious sediment, live and dead coral rubble \\
\hline Encrusting organisms & $\begin{array}{l}\text { 4. Benthic categories with an encrusting morphology, including scleractinian corals, algae and } \\
\text { sponges }\end{array}$ \\
\hline Alcyonarians & 5. Includes all soft corals \\
\hline Scleractinians & $\begin{array}{l}\text { 6. Complex corals: Corals with complex morphologies, including branching, corymbose, digitate, } \\
\text { foliose and tabular forms } \\
\text { 7. Massive corals: Corals with a massive morphology, or solitary forms }\end{array}$ \\
\hline
\end{tabular}


Electivity indices were used to determine if Centropyge species incorporated particular substratum categories into their home patches disproportionately to their availability in the environment. The Vanderploeg \& Scavia (1978) electivity index $\left(E^{*}\right)$ was used because it is considered to be one of the most robust electivity indices (Lechowicz 1982). Positive values indicate that a particular category is used in greater proportions than expected from its availability. Negative values indicate that categories are used less than expected.

An electivity coefficient $\left(E^{*}\right)$ was calculated separately for each species of Centropyge for every substratum category using the formula

$$
E^{*}=\left[W_{i}-(1 / n)\right] /\left[W_{i}+(1 / n)\right]
$$

where $n=$ the number of resource types (substratum categories), $W_{i}=\left(r_{i} / p_{i}\right) / \sum\left(r_{i} / p_{i}\right), r=$ the proportion of resource utilised, and $p=$ the proportion of resources available (Vanderploeg \& Scavia 1978). To compensate for potential variability in the habitat associations exhibited by Centropyge across reef zones, electivities were calculated for the average composition of available habitat types for the reef zone in which the territory occurred. Therefore, mean electivities and standard errors could be calculated for each species.

Finally, canonical correlations were calculated to detect any relationships between the abundance estimates $\left[\log _{10}(x+1)\right]$ of the 3 species of pygmy angelfish and the availability of habitat types in each site/zone across all exposures. No relationship was detected between the abundance of any species with the habitat available at the site level. Therefore, both abundance and habitat were separated into the 3 reef zones at each site to incorporate the effect of depth into the analysis. Canonical coefficients of the species (interset) were then plotted into the space defined by the canonical coefficients of the habitat variables (intraset).

\section{RESULTS}

\section{Distribution and abundance patterns}

Over the 9 sites censused, a total of 910 individuals from the genus Centropyge were recorded around Lizard Island. Relative abundance patterns of the 3 species found were extremely consistent, with Centropyge bicolor always being the most abundant, and C. bispinosa the least abundant (Fig. 2a). There were significant differences in the abundances of Centropyge among exposed, oblique and sheltered sites, and also in the abundances of Centropyge among sites within each exposure (Table 2). Within each exposure type, 2 out of 3 sites tended to be similar in their abun-
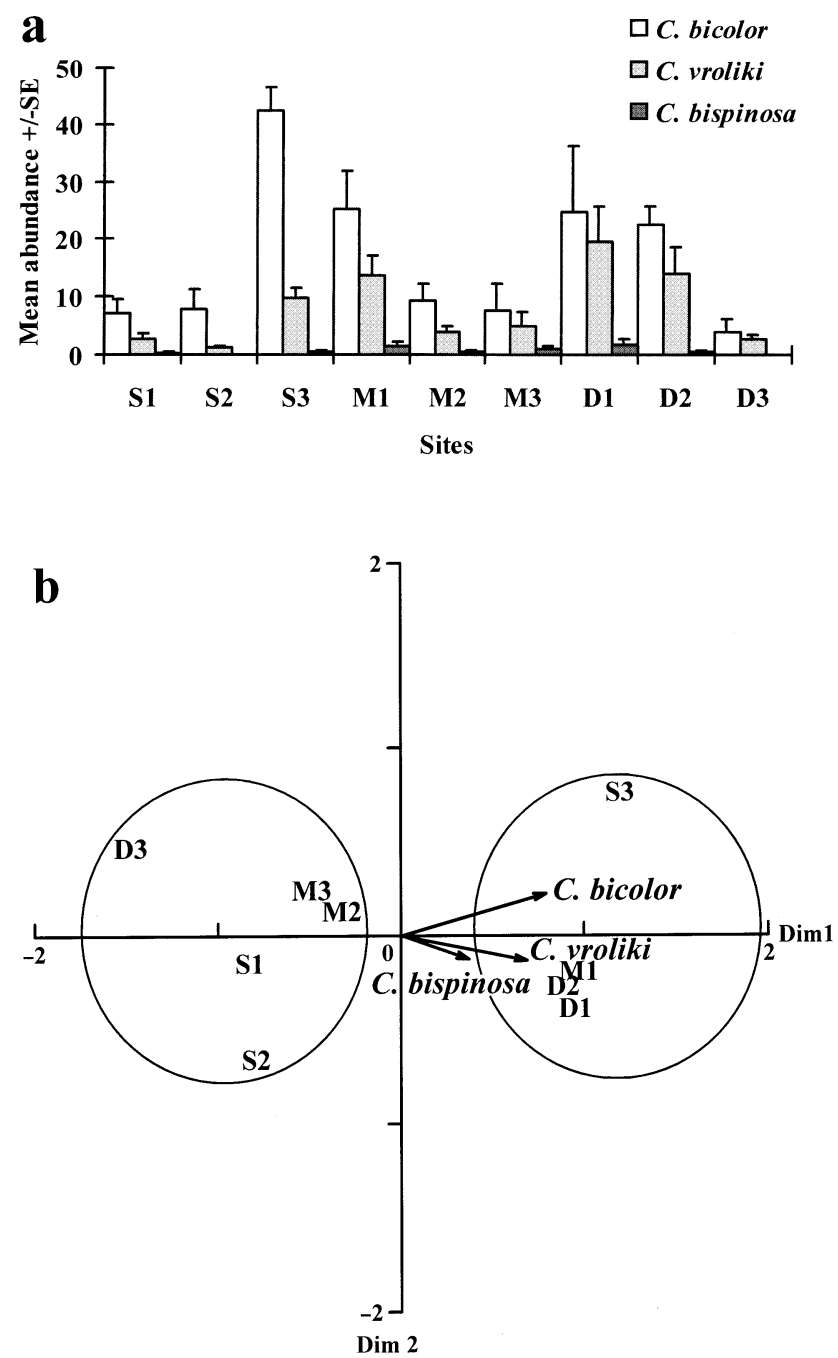

Fig. 2. (a) Mean abundances $( \pm \mathrm{SE}) 1000 \mathrm{~m}^{-2}$ of the 3 Centropyge species at 9 sites including 3 sheltered sites (S1-S3), 3 moderately exposed sites (M1-M3) and 3 directly exposed sites (D1-D3). (b) Non-metric multidimensional scaling of Centropyge mean abundances. Sites are represented by their exposure codes and plotted on a dissimilarity matrix described by the 3 species vectors. The 2 clusters show the results of a complete linkage cluster analysis using Ward's method on the dissimilarities from the matrix

dance and composition of the 3 angelfish species while the third site differed markedly in each case (Fig. 2b). Furthermore, 2 main groups within the 9 sites, separated along dimension 1 of the MDS, were identified by the cluster analysis which do not correspond to exposures (Fig. 2b). Sites S3, M1, D1 and D2 were characterized by high abundances of all 3 species of Centropyge, while sites S2, S3, M2, M3 and D3 exhibited relatively low abundances (see also Fig. 2a). Interestingly, sites with high abundances of Centropyge correspond to reefs that are adjacent to headlands 
Table 2. MANOVA result comparing distribution patterns of Centropyge species among exposure regimes and sites nested within exposures. $\alpha=0.05,{ }^{*}$ significant effects

\begin{tabular}{|lccccc|}
\hline Source of variation & Pillais trace & Hypoth. df & Error df & $F$ & Significance of $F$ \\
\hline Exposure & 1.360 & 6 & 10 & 3.544 & $0.038^{*}$ \\
Site(Exposure) & 0.887 & 18 & 78 & 1.8194 & $0.037^{*}$ \\
\hline
\end{tabular}

around Lizard Island and sites of low abundance corresponded to reefs located in bays (Fig. 1a).

Although all 3 species of Centropyge were most abundant at the same sites, a similar pattern was not observed at the 2 smaller scales examined. At the scale of transects $(100 \times 10 \mathrm{~m})$, high abundances of Centropyge vroliki coincided with high abundances of $C$. bicolor and also $C$. bispinosa, but the abundance estimates of the latter 2 species were not correlated (Table 3). Similarly, C. vroliki were more often seen in $100 \mathrm{~m}^{2}$ quadrats, where either $C$. bicolor and $C$. bispinosa were also found, than would have been expected if the species were distributed independently (Table 3), while the occurrences of the latter 2 species were independent.

The 3 species of Centropyge largely overlapped in their depth distributions over the range surveyed in this study (Fig. 3). All 3 species were found between depths of 1 and $6 \mathrm{~m}$; however Centropyge vroliki and C. bicolor were also found as deep as 9 and $10 \mathrm{~m}$ respectively. Kolmogorov-Smirnov tests using the total frequency of counts for each depth found that there was a significant difference in the depth distribution between $C$. bicolor and $C$. vroliki $(D=0.369, \alpha=0.017$, $\mathrm{p}<0.001$ ), but not between $C$. bispinosa and $C$. bicolor $(D=0.200, \alpha=0.017, \mathrm{p}<0.025)$, or $C$. bispinosa and $C$. vroliki $(D=0.197, \alpha=0.017, \mathrm{p}<0.05)$. C. vroliki was generally found in shallower sections of the reef, with over a quarter of individuals (26\%) between 0 and $1 \mathrm{~m}$ (around the crest) and with the frequency of observation generally declining with depth. In contrast, the depth distribution of $C$. bicolor approximates a normal distribution, with the greatest frequency of observation between 4 and $5 \mathrm{~m}$, and $31 \%$ seen below $6 \mathrm{~m}$.

\section{Habitat availability and use}

The characteristics of the habitat found in home patches varied significantly among species of Centropyge (Table 4). These results reflect the depth distribution of each species and corresponding depthrelated changes in the benthic cover. In a CDA of home patch habitat composition (Fig. 4) the first 2 canonical axes explained $84 \%$ of the variation among habitat characteristics. Differences in depth and the cover of living complex corals accounted for approximately $46 \%$ of the variation among home patches (Can 1, Fig. 4). Complex overgrown corals and topographical complexity of habitats accounted for approximately $38 \%$ of the variation among home patches (Can 2, Fig. 4). In general Centropyge bicolor home patches differed significantly from those of $C$. vroliki, in that they occurred at greater depths and contained proportionately less amounts of live complex corals. C. bispinosa territories occurred in areas
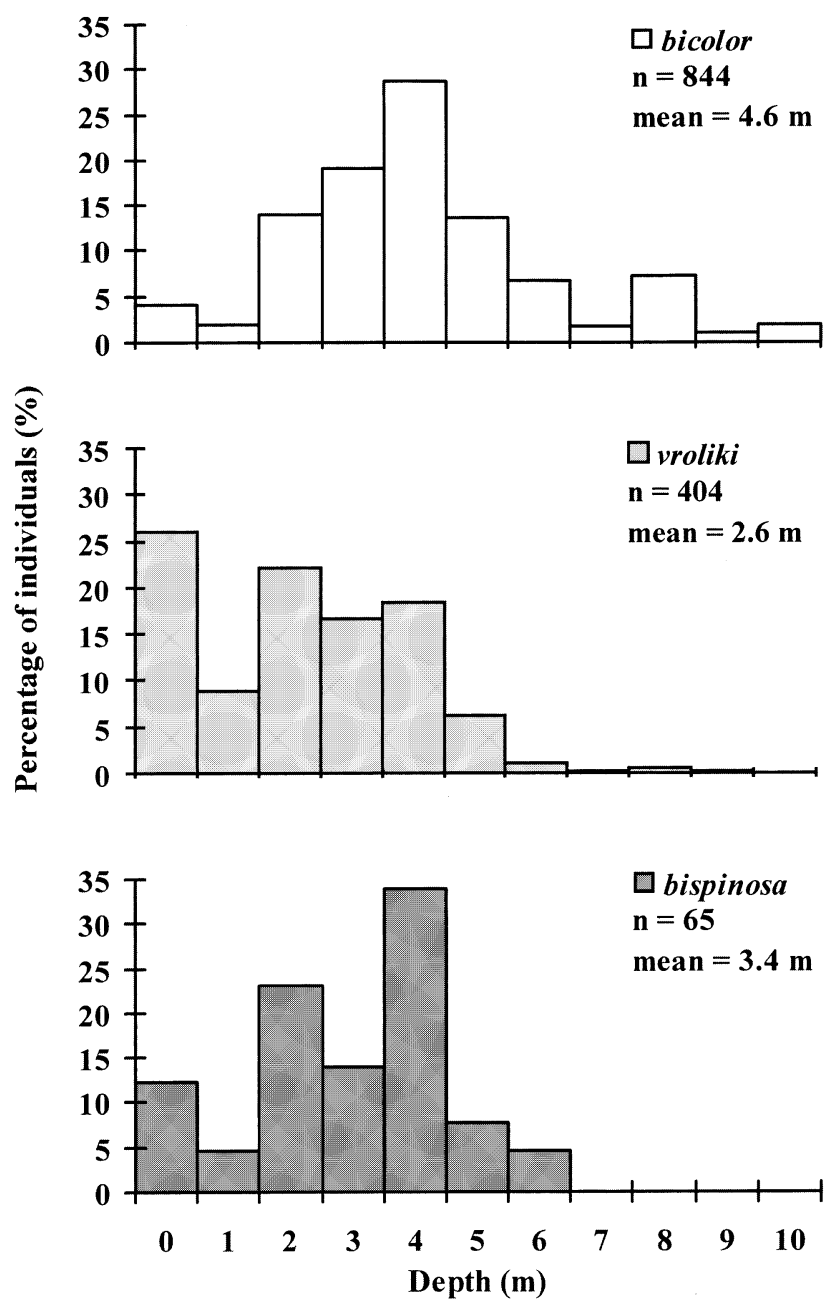

Fig. 3. Depth frequency distributions for the 3 Centropyge species across all sites 
that were intermediate between the other 2 species in depth and the percent cover of living complex corals. However territories were topographically more complex and contained higher proportions of overgrown complex corals than either $C$. vroliki or $C$. bicolor sites. Shelter sites shared by more than 1 species of Centropyge similarly consisted of a higher percentage cover of complex corals overgrown with algae than $C$. bicolor and $C$. vroliki territories.

A comparison of microhabitat use and availability showed that all 3 species appeared to use the same microhabitat (Fig. 5). Overall, home patches for all of the species contained a higher percentage cover of overgrown complex corals than would be expected from the proportion available. Interestingly, there is strong use of overgrown rather than living complex coral substrata, which was not used by any species. Furthermore, all 3 species used non-complex substrata overgrown with algae in approximately the same proportions to which it was available, while most other categories were present in lower proportions in home patches than available.

\section{Correlations between abundance and habitat}

While all 3 Centropyge species appeared to associate with reef patches which had high proportions of complex reef substrata covered in algae, only the abundance of Centropyge bispinosa correlated with the availability of this habitat type (Fig. 6) The canonical correlation indicates that higher numbers of $C$. bispinosa occur where this type of habitat occurs, regardless of the site or reef zone. In contrast, the abundances of $C$. bicolor and $C$. vroliki were not correlated with this commonly used microhabitat. Instead, their abundances were related to the features of depth strata with which each were related (Fig. 4). $C$. bicolor was more abundant at site/zones where there were increased amounts of sand and rubble, while C. vroliki was more abundant in site/zones where there were more complex corals. On a fine scale, these species did not appear to be closely associated with these substrata and used them in lower proportions than expected on the basis of their availability (Fig. 5).
Table 3. Analysis of intermediate and small-scale dispersion patterns of Centropyge species. Values in the top right section are correlation coefficients and p-values (parentheses) between the log abundance at the transect level $\left(1000 \mathrm{~m}^{-2}\right)$. ${ }^{*}$ Significant correlations. Values in the bottom left section are chi-square values for the within transect distribution of Centropyge species $\left(100 \mathrm{~m}^{-2}\right) .{ }^{*}$ Significant non-independence at $\alpha=0.013$. The values in parentheses are phi coefficients of association $(-1<\phi$ $<+1$ ), where a positive value indicates a positive association, and a negative value would indicate negative association

\begin{tabular}{|lccc|}
\hline & C. bicolor & C. vroliki & C. bispinosa \\
\hline C. bicolor & & $0.56(0.001)^{*}$ & $0.31(0.070)$ \\
C. vroliki & $10.64^{*}(+0.17)$ & & $0.44(0.008)^{*}$ \\
C. bispinosa & 0.92 & $17.87^{*}(+0.31)$ & \\
\hline
\end{tabular}

\section{DISCUSSION}

The numerical relationships among the 3 Centropyge species, and their patterns of association with features of the habitat, varied depending on the spatial scale examined. Species were positively associated

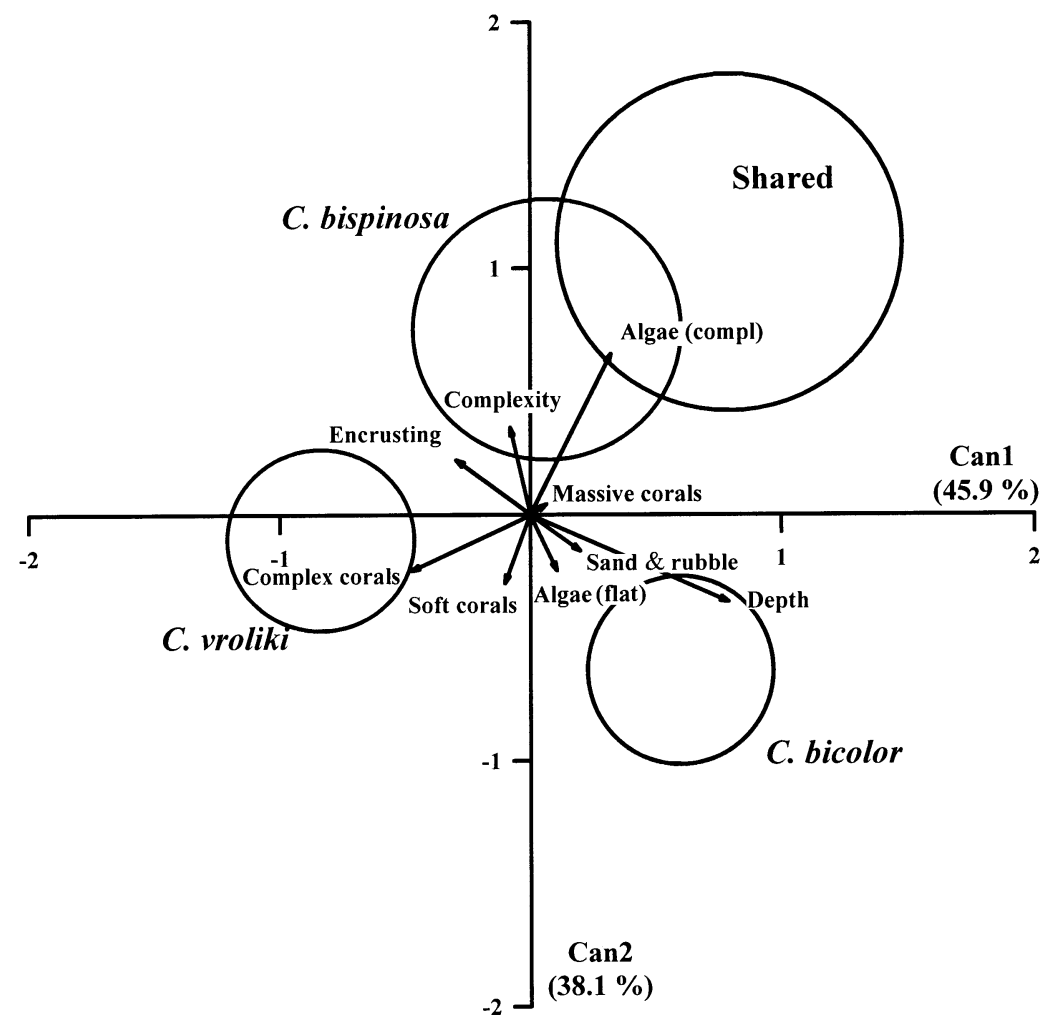

Fig. 4. CDA of the characteristics of shelter sites used by each species of Centropyge. Circles are plotted around the means and the size corresponds to the $95 \%$ confidence ellipses of the canonical scores for the substratum composition and profile characteristics of each species. The proximity of circles indicates the similarity in the habitat used. Vectors are structural coefficients of response variables. Axis labels show the proportion of the variation explained by the plot. Can 1 and Can 2 = canonical variates 1 and 2 
Table 4. MANOVA results for differences in percentage composition of benthic categories, complexity and depth of shelter sites inhabited by Centropyge species. $\mathrm{n}=43,45,22$ for $C$. bicolor, $C$. vroliki and $C$. bispinosa respectively, and $\mathrm{n}=13 \mathrm{for}$ shared sites. $\alpha=0.05,{ }^{*}$ denotes significant effects

\begin{tabular}{|lccccc|}
\hline Source of variation & Pillais trace & Hypoth. df & Error df & $F$ & Significance of $F$ \\
\hline Species & 0.733 & 27 & 339 & 4.061 & $0.0001^{*}$ \\
\hline
\end{tabular}

with each other at some scales but abundances were inversely related at others. Likewise, each species could be positively associated with particular habitat variables at one scale, but appeared not to associate with these habitats at others. Hence studies of these species carried out at different spatial scales could lead to opposite conclusions.

At the largest scale examined, the 3 species of Centropyge recorded the greatest abundance at the same
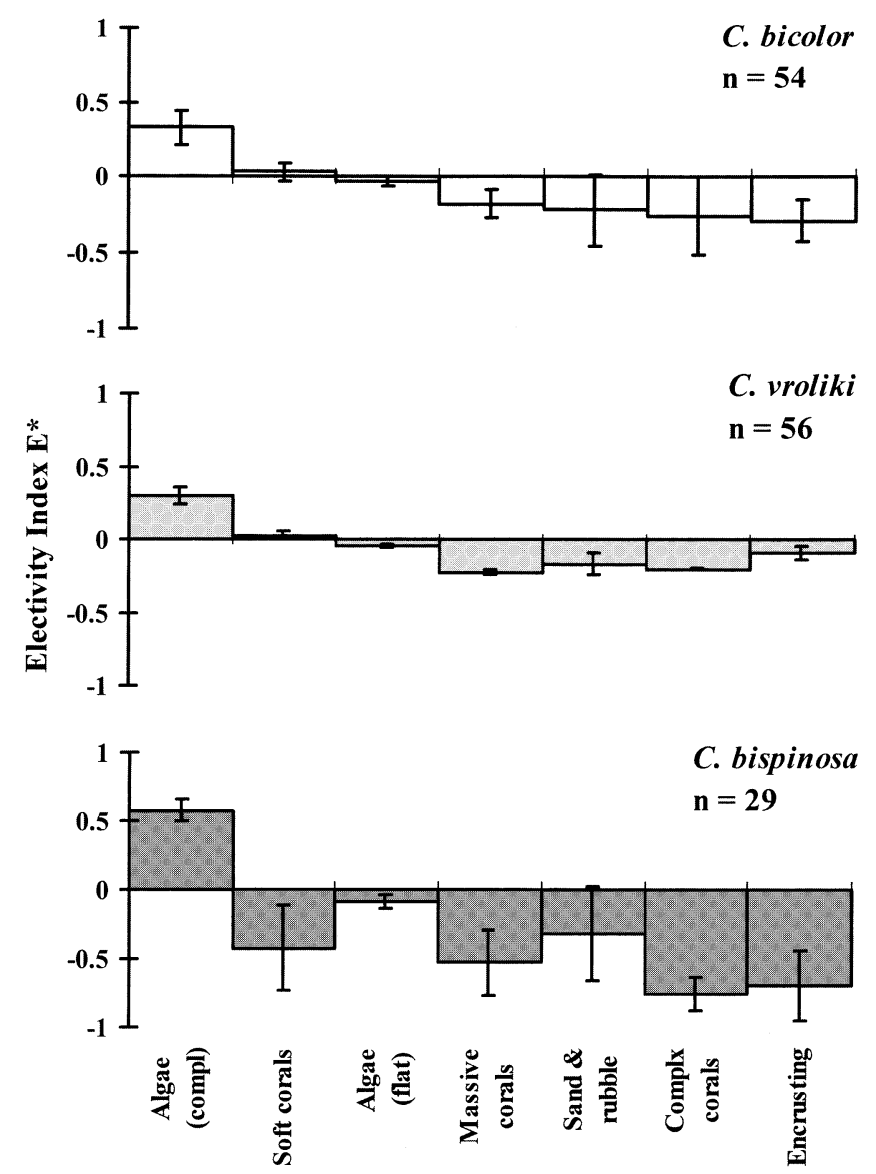

Fig. 5. Patterns of habitat selectivity for Centropyge species. Values are mean electivities (Vanderploeg \& Scavia's $E^{*}$ ) and standard errors. Positive values represent greater use of a habitat type than was available. Negative values represent use of a habitat category less than would be expected from its availability sites around Lizard Island. This suggests that they were responding to the same features of the environment and that there is no partitioning of resources among species at this scale. The factors affecting the distribution and abundance around whole reefs may be phylogenetically conservative in this group. While the species composition for other fish groups has been found to vary at the scale of wind exposures around Lizard Island (Choat \& Bellwood 1985, Kingsford 1992, Meekan et al. 1995, Munday et al. 1997), this was not the case for Centropyge, which appeared to be associated with headlands. The increased abundance of Centropyge at these sites may be the result of preferential settlement by larvae (Victor 1986, Milicich et al. 1992, Tolimieri 1995, Doherty et al. 1996, Light \& Jones 1997) or post-settlement survival (Doherty \& Sale 1985, Shulman \& Ogden 1987, Robertson 1988, Tupper \& Hunte 1994), both of which may result in higher population abundances in more favourable habitats.

There could be several reasons why abundances are greater at headlands. Studies of the distribution of fish larvae around reefs have found that specific wind and current regimes can result in larval retention in particular reef areas (Leis 1986, Kingsford et al. 1991, Sponaugle \& Cowen 1996). Wave refraction and the formation of slicks and eddies may be concentrating larvae at headlands, and densities of Centropyge may be reflecting these differential levels of passive larval supply. Alternatively, high abundances of Centropyge at headlands could be due to the preferential settlement of larvae. However, there is currently no information available on large-scale habitat preferences in Centropyge.

The headlands at Lizard Island may have upwellings or greater current speeds that are known to sustain higher densities of planktivorous fish (Kingsford \& MacDiarmid 1988). It has been observed that populations of Centropyge interrupta at Miyake-jima (Japan) are greater in density along cliff areas where upwelling currents attract aggregations of plankton feeders (Moyer \& Nakazono 1978). It was suggested that this may be due to the faecal materials of planktivores providing an important percentage of the diet of C. interrupta. C. bicolor, C. vroliki and C. bispinosa may be more abundant here because they consume detritus directly, however there is no evidence to sug- 
gest this at present. Alternatively, densities may be higher because increased levels of detritus may enhance the productivity of turf algae that they are known to consume (Moyer \& Nakazono 1978, Aldenhoven 1984, Sakai \& Kohda 1997, Eagle unpubl. data). However, no relationship was found between the abundance of species at headland sites and the presence of turf algae in this study.

It is possible that site-specific differences in mortality, if correlated among species, may also contribute to the distribution patterns observed. Mortality rates have been estimated to vary 10-fold among sites for Centropyge bicolor at Lizard Island (Aldenhoven 1986); however, further investigation is required, with a direct comparison between headland and bay sites.

The greatest species-specific differences in patterns of abundance and habitat-use occurred at the intermediate spatial scale examined. It appears that the species may be partitioning reef areas at scales of $10 \mathrm{~s}$ to $100 \mathrm{~s}$ of metres by depth and lateral location. Centropyge vroliki was most abundant on the reef crest, and C. bicolor was found deeper. There was no significant difference in the depth distribution between $C$. bispinosa and either of these 2 species. This may have been due to the relatively small number of observations of this rarer species obscuring patterns, or its relatively low abundance reducing the need for ecological partitioning. However laterally along the reef margin, C. bispinosa was not found in the same areas as $C$. bicolor at either the 1000 or $100 \mathrm{~m}^{2}$ scale, even though C. vroliki was found where either C. bicolor or C. bispinosa were present. Depth partitioning has been reported for 2 cohabiting Centropyge species in Guam, where C. shepardi replaces C. flavissimus at depths greater than $20 \mathrm{~m}$, with a zone of overlap from 20 to $24 \mathrm{~m}$ (Moyer 1981). Similar depth segregation has been reported for congeners of many other coral reef fishes, such as Chaetodon spp. (Bouchon-Navaro 1986, Fowler 1990), Cephalopholis spp. (Shpigel \& Fishelson 1989), Acanthemblemaria (Clarke 1989), Stegastes spp. (Wellington 1992) and Gobiodon spp. (Munday et al. 1997).

The patterns of abundance of adult Centropyge in these reef zones may reflect differential recruitment to particular reef areas as a result of larval habitat selection. Distribution patterns may correspond with the availability of the reef substrata from which recruits emerge, as found for a number of other reef fishes
(Tolimieri 1995, Booth \& Wellington 1998, Gutierrez 1998). Previous studies have found that adult densities of some reef fish are correlated with recruit densities (Victor 1986) and also that abundances of recruits are correlated with the availability of preferred shelter sites (Shulman 1984, 1985, Victor 1986, Jones 1987 , Light \& Jones 1997, Nemeth 1998, Booth \& Wellington 1998). It is thought that Centropyge bicolor individuals recruit to deeper rubble substrata, whereas C. vroliki recruit to the reef flat (D. R. Bellwood pers. comm.). This suggests that Centropyge may have subtle ontogenetic shifts in resource use after settlement, in particular a habitat shift towards the reef proper from the reef edges. Post-settlement events such as niche shifts are not uncommon for coral reef fishes (McCormick \& Makey 1997, Munday \& Jones 1998, St. John 1999).

Depth distributions may also be maintained by preferential settlement of larvae to areas where adult conspecifics are already located (Sweatman 1983, 1985, Wellington 1992, but see Forrester 1995, 1999, Schmitt \& Holbrook 1999). Or similarly, juvenile persistence may be confined to adult habitats, as has been found for cohabiting Stegastes congeners with complementary depth distributions (Wellington 1992). Thus adult distribution patterns may be driven by a combination of patterns of recruitment, subsequent habitat selection by juveniles and patterns of post-settlement mortality.

On the finest scale examined, all 3 species of Centropyge shared the same pattern of high use of algal- 
covered substratum with a complex morphology, presumably because this type of habitat provides both food and shelter. Aldenhoven (1984) has previously noted that Centropyge bicolor at Lizard Island tended to use patches of habitat which contained both food (algae and detritus) and shelter (corals and crevices). Specific habitat associations have been noted for a number of other species of Centropyge. C. interrupta reportedly prefers areas such as tunnels and caves lacking in Acropora cover (Moyer \& Nakazono 1978). In contrast, $C$. argi territories were found primarily in areas of 'lush coral growth' (Moyer et al. 1983), and similarly, C. ferrugata territories were found to contain higher coral coverage than the surrounding reef (Sakai \& Kohda 1997).

It is as yet unknown whether species actively select particular patches of microhabitat, or simply survive and persist in these areas. One study has quantified Centropyge abundance in a comparison between reefs infested with Acanthaster planci and reefs that were unaffected (Sano et al. 1987). The feeding activities of these coral predators result in reefs retaining their structural complexity but becoming overgrown with turf algae. Interestingly, on living reefs means of 20 individuals (all Centropyge vroliki) $1000 \mathrm{~m}^{-2}$ were recorded, while on affected reefs 30 individuals (of 2 species C. vroliki and C. heraldi) $1000 \mathrm{~m}^{-2}$ were recorded. The same dead reefs were surveyed again after $2 \mathrm{yr}$, by which time they had been reduced to rubble with 0 fish $1000 \mathrm{~m}^{-2}$ recorded. Notably, the living and affected reefs may have had naturally varying abundances of Centropyge which were not due to the effects of $A$. planci. However, it appears possible that overgrown complex habitat is desirable to species of Centropyge elsewhere, and that the availability of this type habitat may affect patterns of distribution and abundance.

In our study, however, no significant correlations were found between abundances of 2 of the Centropyge species and their commonly used micro-habitat, as has been found for other coral reef species (Tolimieri 1998, but see Robertson \& Sheldon 1979). Instead, Centropyge bicolor abundances were correlated with the percentage cover of sand and rubble, a substratum category found in lower proportions in home patches than elsewhere. Similarly, C. vroliki abundances were positively correlated with the percentage cover of complex living corals, which was also present in lower proportions within home patches than elsewhere. Only abundances of $C$. bispinosa were correlated with the micro-habitat type all species were associated with. These patterns of abundance appear to reflect the species' differing broader-scale habitat use patterns rather than their common microhabitat use patterns.
If competition is involved in the determination of patterns of resource use, then it may involve both phylogenetic constraints in the use of some habitat features and partitioning of others. Competition theory predicts greater specialization and partitioning of resource use among species as competition becomes more intense. Conversely, optimal foraging theory predicts that species will become more generalized in their use of resources when competition becomes more intense and resource availability declines (Stephens \& Krebs 1986). This contradiction between competition theory and optimal foraging theory in the role that competition plays in ecological specialization, and thus resource partitioning, has been termed Liem's Paradox. Robinson \& Wilson (1998) proposed that because some resources are easy to use and widely preferred, while others require specialized traits by the consumer, optimally foraging consumers evolve specializations to use non-preferred resources without compromising their abilities to use preferred resources. Therefore, the evolution of specializations to use non-preferred resources can be driven by competition, but the specialists act as generalists whenever their preferred resources are available. It is possible that studies so far have not distinguished between preferred and non-preferred resources, which may be partitioned differently, in their examination of resource partitioning and its subsequent effects on distribution and abundance.

Patterns observed for Centropyge are consistent with Robinson \& Wilson's (1998) proposed solution to Liem's Paradox. For pygmy angelfishes at Lizard Island, the commonly used and possibly preferred microhabitat for all species, overgrown corals, provides both food and shelter and may be easy to use by all species. However, because species tend to be abundant at the same sites, it is possible that this resource is limited in supply and, subsequently, Centropyge vroliki and C. bicolor have diverged to specialize on the reef top and base respectively. Additionally, these 2 species are more abundant in areas with higher proportions of usable habitat, (i.e. complex corals, and sand and rubble respectively) rather than the most used microhabitat. C. bispinosa does not appear to use alternative habitats, which may explain why it is extremely rare at this location, as ecological factors which correlate with rarity include specialised habitat requirements and their availability (Brown et al. 1995) and a poor ability to establish in new areas (Glazier 1980, Rabinowitz 1981).

At some sites, individuals of more than 1 species of Centropyge were observed to share the same home patches and to forage together. This has also been observed for cohabiting Centropyge species elsewhere (Moyer \& Nakazono 1978, Thresher 1982). Significantly, these shared home patches also contained greater proportions of the most used habitat type than 
the single species patches inhabited by groups of $C$. bicolor or C. vroliki. Very little aggression among cohabiting species was observed and this suggests that the intermediate-scale resource partitioning apparent among the species of Centropyge at Lizard Island may not be due to direct competitive displacement among individuals. Instead, it may be the result of the socalled 'ghost of competition past' (Connell 1980) or simply 'individualistic responses' to resources (Ebeling \& Laur 1986).

The results from our study demonstrate that patterns of distribution and abundance among closely related coral reef fishes vary among spatial scales. Species tended to be positively associated and ecologically similar at the largest and smallest spatial scales examined, but divergent at an intermediate scale. Although all species are relatively rare, they tend to be concentrated at a small number of sites and are virtually absent elsewhere. Because they have similar fine-scale habitat use patterns, they are often found sharing the same territorial sites. It is only at an intermediate scale that the species have complementary distribution and abundance patterns. The role of inter-specific competition in the formation of these patterns needs further investigation. While it is unclear exactly how much habitat partitioning is necessary before competitive interactions are reduced enough to allow coexistence, the partitioning of Centropyge species on intermediate scales might enable all 3 species to coexist in relatively small areas of reef where they reach their greatest abundance.

Acknowledgements. We would like to thank the staff of the Lizard Island Research Station for use of their facilities and Michael Marnane for assistance in the field. Many thanks to Philip Munday, and the 4 anonymous reviewers for their comments which helped to improved the manuscript. This research was part of an honours degree completed by J.V.E. supported by a grant to G.P.J. from the Australian Research Council Large Grant Scheme.

\section{LITERATURE CITED}

Aldenhoven JM (1984) Social organisation and sex change in an angelfish, Centropyge bicolor. $\mathrm{PhD}$ thesis, Macquarie University, Sydney, NSW

Aldenhoven JM (1986) Local variation in mortality rates and life-expectancy estimates of the coral-reef fish Centropyge bicolor (Pisces: Pomacanthidae). Mar Biol 92: 237-244

Bauer JA, Bauer SE (1981) Reproductive biology of pigmy angelfishes of the genus Centropyge (Pomacanthidae). Bull Mar Sci 31(3):495-513

Booth DJ, Wellington GM (1998) Settlement preferences in coral-reef fishes: effects on patterns of adult and juvenile distributions, individual fitness and population structure. Aust J Ecol 23:274-279
Bouchon-Navaro Y (1986) Partitioning of food and space resources by chaetodontid fishes on coral reefs. J Exp Mar Biol Ecol 103:21-40

Brown JH, Mehlman DW, Stevens GC (1995) Spatial variation in abundance. Ecology 76:2028-2043

Choat JH, Bellwood DR (1985) Interactions amongst herbivorous fishes on a coral reef: influence of spatial variation. Mar Biol 89:221-234

Clarke RD (1989) Population fluctuation, competition and microhabitat distribution of two species of tube blennies, Acanthemblemaria (Teleostei: Chaenopsidae). Bull Mar Sci 44(3):1174-1185

Clarke RD (1994) Habitat partitioning by chaenopsid blennies in Belize and the Virgin Islands. Copeia 1994(2):398-405

Colwell RK (1973) Competition and coexistence in a simple tropical community. Am Nat 107:737-760

Connell JH (1980) Diversity and the coevolution of competitors, or the ghost of competition past. Oikos 35:131-138

Doherty PJ (1983) Tropical territorial damselfishes: is density limited by aggression or recruitment? Ecology 64(1): 176-190

Doherty PJ, Sale PF (1985) Predation on juvenile coral reef fishes: an exclusion experiment. Coral Reefs 4:225-234

Doherty PJ, Williams DM (1988) The replenishment of coral reef fish populations. Oceanogr Mar Biol Annu Rev 26: 487-551

Doherty PJ, Kingsford M, Booth D, Carleton J (1996) Habitat selection before settlement by Pomacentrus coelestis. Mar Freshw Res 47:391-399

Ebeling AW, Laur DR (1986) Foraging in surfperches: resource partitioning or individualistic responses? Environ Biol Fish 16(1-3):123-133

Ebersole JP (1985) Niche separation of two damselfish species by aggregation and differential microhabitat utilization. Ecology 66:14-20

Eckert GJ (1985) Settlement of coral reef fishes to different natural substrata and at different depths. Proc 5th Int Coral Reef Congr, Tahiti 5:385-396

Forrester GE (1995) Strong density-dependent survival and recruitment regulate the abundance of a coral reef fish. Oecologia 103:275-282

Forrester GE (1999) The influence of adult density on larval settlement in a coral reef fish, Coryphopterus glaucofraenum. Coral Reefs 18:85-89

Fowler AJ (1990) Spatial and temporal patters of distribution and abundance of chaetodontid fishes at One Tree Reef, southern GBR. Mar Ecol Prog Ser 64:25-38

Gaston KJ (1994) Rarity. Chapman and Hall, London

Glazier DS (1980) Ecological shifts and the evolution of geographically restricted species of North American Peromyscus (mice). J Biogeogr 7:63-83

Green AL (1996) Spatial, temporal and ontogenetic patterns of habitat use by coral reef fishes (Family Labridae). Mar Ecol Prog Ser 133:1-11

Gutierrez L (1998) Habitat selection by recruits establishes local patterns of adult distribution in two species of damselfishes: Stegastes dorsopunicans and S. planifrons. Oecologia 115:268-277

Itzkowitz M (1977) Spatial organisation of the Jamaican damselfish community. J Exp Mar Biol Ecol 28:217-241

Jennings S, Boulle DP, Polunin NVC (1996) Habitat correlates of the distribution and biomass of Seychelles reef fishes. Environ Biol Fish 46:15-25

Jones GP (1987) Some interactions between residents and recruits in two coral reef fishes. J Exp Mar Biol Ecol 114: $169-182$

Jones GP (1988) Experimental evaluation of the effects of habi- 
tat structure and competitive interactions on the juveniles of two coral reef fishes. J Exp Mar Biol Ecol 123:115-126

Jones GP, Kaly UL (1995) Conservation of rare, threatened and endemic marine species in Australia. In: Zann LP, Kailola PK (eds) State of the marine environment report to australia. Technical annex 1; the marine environment. Ocean Rescue 2000 Program. Department of the Environment, Sport and Territories

Kingsford MJ (1992) Spatial and temporal variation in predation on reef fishes by coral trout (Plectromus leopardus, Serranidae). Coral Reefs 11:193-198

Kingsford MJ, MacDiarmid AB (1988) Interrelations between planktivorous reef fish and zooplankton in temperate waters. Mar Ecol Prog Ser 48:103-117

Kingsford MJ, Wolanski E, Choat JH (1991) Influence of tidally induced fronts and Langmuir circulations on distribution and movements of pre-settlement fishes around a coral reef. Mar Biol 109:167-180

Lechowicz MJ (1982) The sampling characteristics of electivity indices. Oecologia 52:22-30

Leis JM (1986) Vertical and horizontal distribution of fish larvae near coral reefs at Lizard Island, Great Barrier Reef. Mar Biol 90:505-516

Light PR, Jones GP (1997) Habitat preference in newly settled coral trout (Plectropomus leopardus, Serranidae). Coral Reefs 16:117-126

Lobel PS (1978) Diel, lunar and seasonal periodicity in the reproductive behaviour of the pomacanthid fish, Centropyge potteri and some other reef fishes in Hawaii. Haw J Pac Sci 32(2):193-207

MacArthur RH (1969) Patterns of communities in the tropics. Biol J Linn Soc 1:19-30

McAfee ST, Morgan SG (1996) Resource use by five sympatric parrotfishes in the San Blas Archipelago, Panama. Mar Biol 125:427-437

McCormick MI (1994) Comparison of field methods for measuring surface topography and their associations with a tropical reef fish assemblage. Mar Ecol Prog Ser 112:87-96

McCormick MI, Makey LJ (1997) Post-settlement transition in coral reef fishes: overlooked complexity in niche shifts. Mar Ecol Prog Ser 153:247-257

Meekan MG, Steven ADL, Fortin MJ (1995) Spatial patterns in the distribution of damselfishes on a fringing coral reef. Coral Reefs 14:151-161

Milicich MJ, Meekan MG, Doherty PJ (1992) Larval supply: a good predictor of recruitment of three species of reef fish (Pomacentridae). Mar Ecol Prog Ser 86:153-166

Moyer JT (1981) Interspecific spawning of the pygmy angelfishes Centropyge shepardi and Centropyge bispinosus at Guam. Micronesica. 17(1-2):119-124

Moyer JT, Nakazono A (1978) Population structure, reproductive behaviour and protogynous hermaphroditism in the angelfish Centropyge interrupta at Miyake-jima, Japan. Jpn J Ichthyol 25(1):25-39

Moyer JT, Thresher RE, Colin PL (1983) Courtship, spawning and inferred social organisation of American angelfishes (Genera Pomacanthus, Holacanthus and Centropyge). Environ Biol Fish 9(1):25-39

Munday PL, Jones GP (1998) The ecological implications of small body size among coral-reef fishes. Oceanogr Mar Biol Annu Rev 36:373-411

Munday PL, Jones GP, Caley MJ (1997) Habitat specialisation and the distribution and abundance of coral-dwelling gobies. Mar Ecol Prog Ser 152:227-239

Nemeth RS (1998) The effect of natural variation in substrate architecture on the survival of juvenile bicolor damselfish. Environ Biol Fish 53:129-141
Ormond RFG, Roberts JM, Jan RQ (1996) Behavioural differences in microhabitat use by damselfishes (Pomacentridae): implications for reef fish biodiversity. J Exp Mar Biol Ecol 202:85-95

Pianka ER (1966) Latitudinal gradients in species diversity: a review of concepts. Am Nat 100:33-46

Pitts PA (1991) Comparative use of food and space by three Bahamian butterflyfishes. Bull Mar Sci 48(3):749-756

Rabinowitz D (1981) Seven forms of rarity. In: Synge H (ed) The biological aspects of rare plant conservation. John Wiley \& Sons, Chichester, p 205-217

Roberts CM (1987) Experimental analysis of resource sharing between herbivorous damselfish and blennies on the Great Barrier Reef. J Exp Mar Biol Ecol 111:61-75

Robertson DR (1984) Cohabitation of competing territorial damselfishes on a Caribbean coral reef. Ecology 65: 1121-1135

Robertson DR (1988) Abundances or surgeonfishes on patchreefs in Caribbean Panama: due to settlement, or postsettlement events. Mar Biol 97:495-501

Robertson DR (1996) Interspecific competition controls abundance and habitat use of territorial Caribbean damselfishes. Ecology 77:885-899

Robertson DR, Gaines SD (1986) Interference competition structures habitat use in a local assemblage of coral reef surgeonfishes. Ecology 67(5):1372-1383

Robertson DR, Lassig B (1980) Spatial distribution patterns and coexistence of a group of territorial damselfishes from the Great Barrier Reef. Bull Mar Sci 30:187-203

Robertson DR, Sheldon JM (1979) Competitive interactions and the availability of sleeping sites for a diurnal coral reef fish. J Exp Mar Biol Ecol 40:285-298

Robinson BW, Wilson DS (1998) Optimal foraging, specialization and a solution to Liem's Paradox. Am Nat 151(3): $223-235$

Roughgarden J (1974) Species packing and the competition function with illustrations from coral reef fish. Theor Popul Biol 5:163-186

Sakai Y, Kohda M (1997) Harem structure of the protogynous angelfish, Centropyge ferrugata (Pomacanthidae). Environ Biol Fish 49:333-339

Sale PF (1975) Patterns of use space in a guild of territorial reef fishes. Mar Biol 29:89-97

Sale PF (1977) Maintenance of high diversity in coral reef fish communities. Am Nat 111(978):337-359

Sale PF (1978) Coexistence of coral reef fishes - a lottery for living space. Environ Biol Fish 3(1):85-102

Sale PF (1991) Habitat structure and recruitment in coral reef fishes. In: Bell SS, McCoy ED, Mushinsky HR (eds) Habitat structure: the physical arrangement of objects in space. Chapman and Hall, London

Sale PF (1998) Appropriate spatial sales for studies of reef fish. Aust J Ecol 23:202-208

Sale PF, Doherty PJ, Eckert GJ, Douglas WA, Ferrell DJ (1984) Large scale spatial and temporal variation in recruitment to fish populations on coral reefs. Oecologia 64:191-198

Sano M (1990) Patterns of habitat and food utilization in two coral-reef sandperches (Mugiloididae): competitive or noncompetitive coexistence. J Exp Mar Biol Ecol 140:209-223

Sano M, Shimizu M, Nose Y (1987) Long-term effects of destruction of hermatypic corals by Acanthaster planci infestation on reef fish communities at Iriomote Is., Japan. Mar Ecol Prog Ser 37:191-199

Schmitt RJ, Holbrook SJ (1999) Settlement and recruitment of three damselfish species: larval delivery and competition for shelter space. Oecologia 118:76-86 
Seber GAF (1984) Multivariate observations. John Wiley \& Sons, New York

Shpigel M, Fishelson L (1989) Habitat partitioning between species of the genus Cephalopholis (Pisces: Serranidae) across the fringing reef of the Gulf of Aquaba. Mar Ecol Prog Ser 58:17-22

Shulman MJ (1984) Resource limitation and recruitment patterns in a coral reef fish assemblage. J Exp Mar Biol Ecol 74:85-109

Shulman MJ (1985) Coral reef fish assemblages: intra- and inter-specific competition for shelter sites. Environ Biol Fish 13(2):81-92

Shulman MJ, Ogden JC (1987) What controls tropical reef fish populations: recruitment or benthic mortality? An example in the Caribbean reef fish Haemulon flavolineatum. Mar Ecol Prog Ser 39:233-242

Sokal RR, Rohlf FJ (1995) Biometry. WH Freeman and Company, New York

Sponaugle S, Cowen RK (1996) Nearshore patterns of coral reef fish larval supply to Barbados, West Indies. Mar Ecol Prog Ser 133:13-28

Stephens DW, Krebs JR (1986) Foraging theory. Princeton University Press, Princeton, NJ

St. John J (1999) Ontogenetic changes in the diet of the coral reef grouper Plectropomus leopardus (Serranidae): patterns in taxa, size and habitat of prey. Mar Ecol Prog Ser 180:233-246

Sweatman HPA (1983) Influence of con-specifics on choice of settlement sites by larvae of two pomacentrid fishes (Dascyllus aruanus and D. reticulatus) on coral reefs. Mar Biol 75:225-229

Sweatman HPA (1985) The influence of adults of some coral reef fishes on larval recruitment. Ecol Monogr 55(4): 469-485

Talbot FHA (1965) A description of the coral structure of Tutia Reef (Tanganyika Territory, East Africa), and its fish

Editorial responsibility: Otto Kinne (Editor), Oldendorf/Luhe, Germany fauna. Proc Zool Soc Lond 145:431-470

Talbot FH, Russell BC, Anderson GRV (1978) Coral reef fish communities: unstable high diversity systems. Ecol Monogr 1978:425-440

Thresher RE (1982) Courtship and spawning in the emperor angelfish Pomacanthus imperator, with comments on reproduction by other pomacanthid fishes. Mar Biol 70: $149-156$

Tolimieri N (1995) Effects of microhabitat characteristics on the settlement and recruitment of a coral reef fish at two spatial scales. Oecologia 102:52-63

Tolimieri N (1998) Contrasting effects of microhabitat use on large-scale adult abundance in two families of Caribbean reef fishes. Mar Ecol Prog Ser 167:227-239

Tupper M, Hunte W (1994) Recruitment dynamics of coral reef fishes in Barbados. Mar Ecol Prog Ser 108:225-235

Vanderploeg HA, Scavia D (1978) Two electivity indices for feeding with special reference to zooplankton grazing. J Fish Res Board Can 36:362-365

Victor BC (1983) Recruitment and population dynamics of a coral reef fish. Science 219:419-420

Victor BC (1986) Larval settlement and juvenile mortality in a recruitment-limited coral reef fish population. Ecol Monogr 56(2):145-160

Waldner RE, Robertson DR (1980) Patterns of habitat partitioning by eight species of territorial Caribbean damselfishes (Pisces: Pomacentridae). Bull Mar Sci 30:171-186

Wellington GM (1992) Habitat selection and juvenile persistence control the distribution of two closely related Caribbean damselfishes. Oecologia 90:500-508

Williams DM (1982) Patterns in the distribution of fish communities across the central Great Barrier Reef. Coral Reefs 1:35-43

Williams DM (1991) Patterns and processes in the distribution of coral reef fishes. In: Sale PF (ed) The ecology of fishes on coral reefs. Academic Press, San Diego, p 437-473

Submitted: December 14, 1999; Accepted: September 6, 2000 Proofs received from author(s): March 22, 2001 